The bungalows for married couples are adjusted to house five people and include an entrance-hall, a living-room, an adapted kitchen with a counter for passing dishes and an adjacent table, three bedrooms, two toilets and two bathrooms.

We have been particularly pleased to tell you of the realisations of social housing in Belgium, realisations which are relative to the housing of the physically disabled, mainly paraplegics. We hope that these first achievements will permit us to solve quickly the problems of the social regrouping of paraplegics, as otherwise all the efforts entailed by their rehabilitation would remain incomplete.

We thank most sincerely the head staff of the 'Institut National du Logement' for having given us the relevant documents, and in particular the General Secretary Mr. Crappe, and Mr. De Beuyker, delegate of mission at the Institute, who carried out the enquiry.

\title{
THE MARRIED LIFE OF PARAPLEGICS AND TETRAPLEGICS
}

\author{
L. Guttmann, C.B.E., M.D., F.R.C.P., F.R.C.S. \\ National Spinal Injuries Centre, \\ Stoke Mandeville Hospital, Aylesbury, Bucks., England
}

IT is the aim of everyone concerned with the social resettlement of spinal cord sufferers to return as many of them as possible to their homes to live a near normal life within the community. Naturally, one would expect that a disablement of a magnitude such as paraplegia and tetraplegia would set up in its wake difficult problems in the domestic resettlement of these severely disabled people, particularly in their marital adjustment. This is doubtless true, to a certain extent. Nevertheless, it is an undeniable fact that many subjects who were already married at the time of their spinal cord injury or disease have continued their married life successfully for many years, and others who were single have started their married life after having become paraplegics or tetraplegics.

Major statistical surveys on the marital life of a particular number of paraplegics and tetraplegics do not exist, apart from one published in 1962 by Comarr of the Spinal Unit at Long Beach Veterans Hospital, U.S.A., on 859 paraplegic and tetraplegic veterans of the U.S. Army.

In the present paper, a statistical survey is presented on the marital status of I 505 living traumatic paraplegics and tetraplegics of marriageable age treated at Stoke Mandeville, 527 of whom were ex-service pensioners. There were I3 16 men and 189 women.

The marital status of these people before admission is given in Table I, showing 674 ( 44.8 per cent.), of whom 69 were women, married and living with their partners. This figure includes marriages both before and after injury, the great majority being after injury. A total of 777 ( $5 \mathrm{I} \cdot 8$ per cent.), amongst them 99 women, were single, and 15 not included in the figure of 777 were known to be cohabiting. Before admission 17 more were divorced or separated and 22 were widowed.

Out of the 777 single ones in Table I 302 married after admission, the majority (267) being paraplegics. Table II shows the division of complete and incomplete lesions amongst the married paraplegics and tertaplegics of this group. The majority of paraplegic men who married normal women were compete lesions (I4I) 
out of 226), while the majority of tetraplegic men who married normal women were incomplete lesions (20 out of 33 ). No difference in number was found between complete and incomplete lesions in paraplegic women who married normal men. Of our male traumatics, II married eight of our female traumatics, while three more of our traumatic females married paralysed men not treated at Stoke Mandeville. If one adds the 302 of this group to the 674 who were living with their married partners at the time of their admission to Stoke Mandeville, this brings the total of married paralysed out of the I 505 under discussion to 976 (64.9 per cent.). Amongst them were 192 tetraplegics.

\section{TABLE I}

Marital Status of I 505 Paraplegics and Tetraplegics before Admission

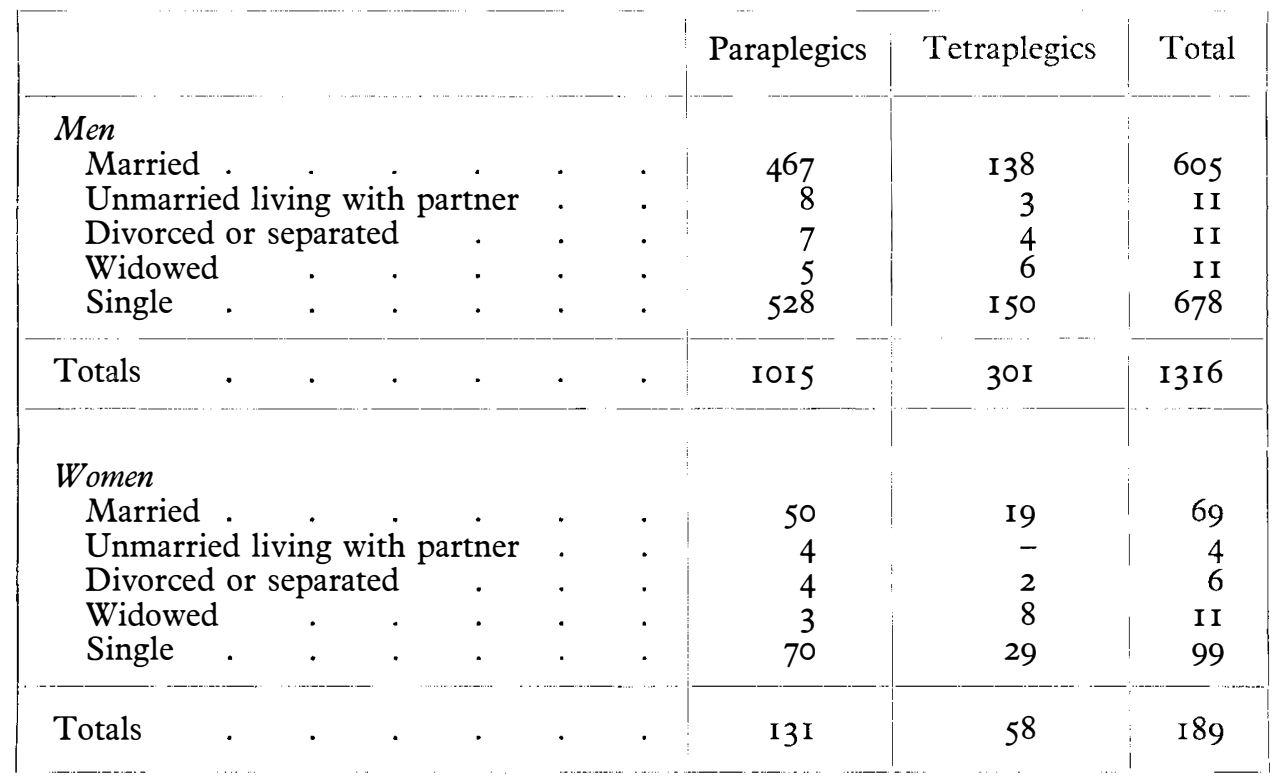

\section{Divorce}

Table III gives data of divorce in these two groups after admission. The total of divorces of the two groups is 57 out of 976 . If one adds the 17 already divorced before admission this bring the number of divorces out of a total of IOI 5 marriages to 74 or $7 \cdot 3$ per cent.

In previous publications during the last I0-I 6 years, it has been reported that in a number of patients with severe lesions of the spinal cord sexual readjustment is possible and that the former widespread belief that these people are necessarily permanently impotent and sterile is unfounded (Munro et al., I948; Guttmann, 1953, 1960; Comarr \& Bors, I955; Talbot, I955; Zeitlin et al., 1957). Moreover, the advances made in the rehabilitation of spinal cord sufferers and their increased survival rate has influenced the adoption authorities in recent years to allow these severely disabled people to adopt children. Table IV shows the result of our 
material. A total of 205 children were fathered by 108 paraplegic and tetraplegic men; I6 paralysed women amongst them a woman with a tetraplegia below C6, bore 22 children. Fifty-nine paralysed men, amongst them four tetraplegics, adopted 79 children. It may be noted here that in this figure I 3 step-children of I I paraplegics who married widows with children are also included. Of these II marriages, eight took place after admission to Stoke Mandeville.

\section{TABLE II}

Marriages after Admission

\begin{tabular}{|c|c|c|c|c|}
\hline Men & Paraplegic men to: & Normal Women & Paraplegic Women & Total \\
\hline Complete & . & I4 I & 9 & I 50 \\
\hline Incomplete & e . & 85 & 2 & 87 \\
\hline \multicolumn{5}{|c|}{ Tetraplegic men to: } \\
\hline Complete & . & 13 & - & 13 \\
\hline \multirow[t]{2}{*}{ Incomplete } & e . & 20 & - & 20 \\
\hline & & 259 & II & 270 \\
\hline Women & araplegic women to: & Normal Men & $\begin{array}{r}\text { Paraplegic } \\
\text { or Polio Men }\end{array}$ & Total \\
\hline Complete & . & IO & 9 & 19 \\
\hline Incomplete & e . & IO & I & I I \\
\hline \multicolumn{5}{|c|}{ Tetraplegic women to: } \\
\hline Complete & . & - & I & I \\
\hline Incomplete & e. & I & - & I \\
\hline Totals & . & $2 \mathrm{I}$ & I I & 32 \\
\hline
\end{tabular}

\section{DISCUSSION}

In analysing the data given, it can be first stated that paraplegia as well as tetraplegia as such is not a hindrance to a happy married life. This applies to those who were already married at the time of injury as well as to those who married after their spinal cord lesion. It also applies to both paraplegics and tetraplegics with complete and incomplete lesions. Furthermore, it does not make any difference whether normal women married paraplegic or tetraplegic men (and this is no doubt the majority), whether normal men married paraplegic women or whether paraplegics married amongst themselves. Many stories of great devotion in this respect could be told, but it is beyond the scope of this paper to go into details. The fact that divorces in the group already married before their paraplegia are less frequent than in the group who married after, tends to show that in the former group there has already been a basis of normal married life and companionship and therefore the loyalty of the normal partner is greater. In this connection, ten men and four women may be mentioned who, on admission, were known to have been cohabiting. Only two of these partnerships have broken up since; two paralysed men married 


\section{TABLE III}

Married at time of admission to Stoke Mandeville Hospital

Divorced or Separated after Admission

$$
\text { Mandeville Hospital }
$$

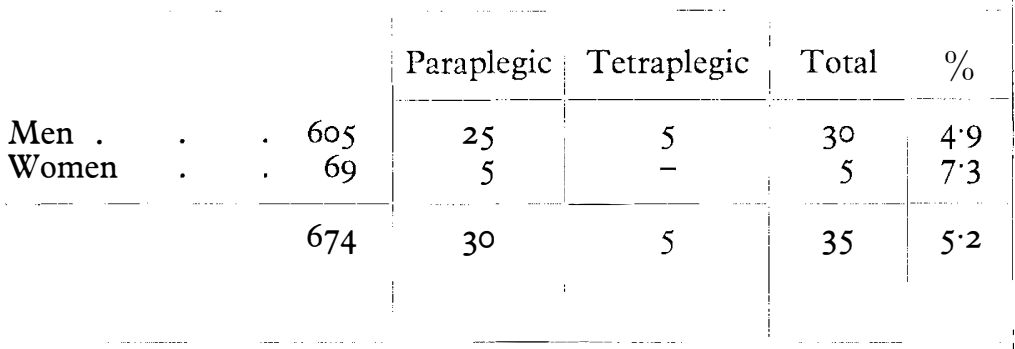

Married after admission to Stoke Mandeville Hospital
Married and Divorced after Admission

\begin{tabular}{|c|c|c|c|c|c|}
\hline & & Paraplegic & Tetraplegic & Total & $\%$ \\
\hline Men & 270 & I6 & 4 & 20 & $7 \cdot 4$ \\
\hline Women & 29 & I & I & 2 & 7.0 \\
\hline & 299 & 17 & 5 & 22 & $7 \cdot 36$ \\
\hline
\end{tabular}

TABLE IV

Children

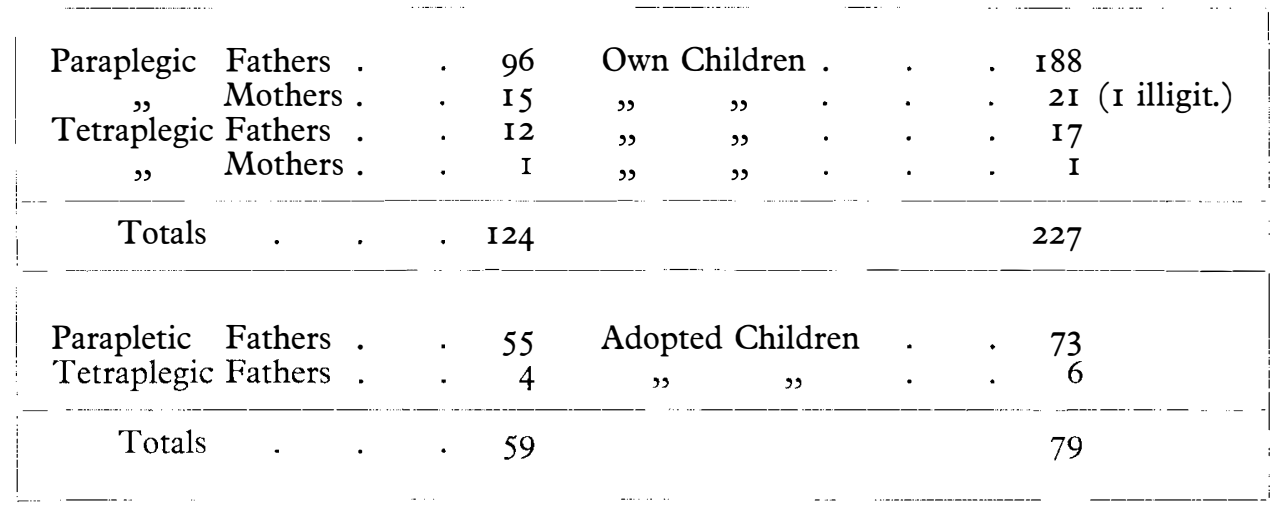


their partners and the others are in status quo. The motivation which initiates normal people to marry spinal paraplegics appears to be in the majority of cases love and affection, but in some cases it has been loyalty to the man or girl to whom they were already engaged before the paraplegia or tetraplegia. Furthermore, with some women it has been a highly developed mothering instinct and in others no doubt financial security. The latter applies in particular to widows with young children but also to women who know that the prospective husband's pension or other income will provide a life of security. An extraordinary case is a married woman who became a bigamist by 'marrying' a tetraplegic service pensioner. She was not prosecuted for committing bigamy but was charged with stealing his money. The tetraplegic in question, far from being discouraged by this disappointment, has since married another woman and is living happily with her.

This brings me to the interesting problem of divorce. At the time of the statistic, 22 paraplegics and tetraplegics of the 74 mentioned above had since remarried, thus bringing the total number remaining divorced to 52 or $5^{\circ}$ I per cent. of the total number married. This, I feel, is infinitely smaller than one would expect in people with such a profound disablement. In fact, it is only slightly higher than the percentage of divorces amongst the general population in Great Britain, which according to the last census in I96I was about I per cent. It is interesting to compare these figures with that of $4 \mathrm{I} 2$ out of 858 married paraplegics and tetraplegics given by Comarr in his statistics of 1962 . The divorce rate after injury was 27-39 per cent. Although this figure is higher than that of the general population of the U.S.A. (26 per cent.), it is below that of the population in Los Angeles, County of California (45-49 per cent.), the highest in the U.S.A. However, the divorce rate of patients who were married for the first time after injury varied between ro per cent. for the non-military service-connected patients and 24 per cent. for the service-connected ones.

What are the motives for divorce? It can first be stated that revulsion to the paraplegia as such was as a rule not found to be a significant reason for divorce, whatever the level and completeness of the lesion. Actually, one woman married to a man with a low cauda equina lesion who regained his walking abilities ran away with a man with a complete paraplegia below TII. In some cases, especially those where marriage took place in haste or when the normal partner was perhaps motivated by reasons other than love and affection-such as pity, financial reasons, etc.-when faced with realities the marriage broke up. Incompatibility was also a reason, especially in young and immature people who married hastily or in psychopathic individuals. For instance, one young woman who was already divorced from an actor before her paraplegia married a writer, but the marriage broke up after she became a paraplegic. She then married an officer of the R.A.F. with a very incomplete cauda equina lesion, from whom she became separated when her mental condition deteriorated. Another example is that of a Yugoslav paraplegic who came to Stoke Mandeville and who, on return to his own country, left his normal wife to marry a British paraplegic girl, whom he met at Stoke Mandeville. They married and lived in Yugoslavia, but the paraplegic wife left him because she said he became intolerable. She returned to England, obtained a divorce and is now married to an able-bodied man. A further instance of incompatibility is that of a woman with a partial paraplegia who had a I7-year-old daughter from her first marriage. She married a man 20 years younger than herself. Naturally, the marriage did not last. 
Sexual frustration of the wife, regardless of whether it concerns a woman who had children by her husband before his paraplegia or after marrying a paraplegic, certainly accounts for divorce in some cases, especially if the normal woman becomes involved with another man and becomes pregnant. Sexual desire outside marriage has accounted for several of the divorces. One extreme case in this respect is that of a woman who, after having had no less than II children, left her paraplegic husband to live with another man. This may also apply to paraplegic women, although more rarely. One paraplegic woman left her husband to live with another man, by whom she had an illegitimate child. The most tragic case in this group is the case of a young tetraplegic woman with a lesion below C6-a former beauty queen-who was engaged at the time of her car accident. Her fiancé married her after her discharge from hospital and she had a child by him, but alréady at that time he had formed an association with another girl who had also become pregnant by him. He left his paraplegic wife shortly afterwards and married the other girl.

It has been our experience that paralysed women as well as paralysed men, whose partners have left them for one reason or another, have taken the situation very well and, as already mentioned, quite a number have married again. There was only one exception-a psychopathic non-traumatic paraplegic who, although not included in these statistics, may be mentioned here. He had married a girl in haste and had become increasingly depressed by the unfaithfulness of his wife, and when she eventually left him, refusing to return, he committed suicide.

Finally, a few words on the problem of children of paraplegics and tetraplegics. Our statistics on traumatic paraplegics clearly show that the generalised pessimism of many members of the medical profession regarding potency and sterility in paraplegic men and motherhood in paraplegic women is unfounded. In a previous paper (1963) - 'The paraplegic patient in pregnancy and labour'-I have already discussed the question of motherhood of paraplegic women and have given evidence that, in spite of their severe disablement, they can bear normal children and look after them. Moreover, I have pointed out that confinement by Caesarian section should be limited to extremely rare cases. At that time, 22 babies had been bornI3 boys and nine girls to I 6 paraplegics and quadriplegics. Of the paraplegics, four had two children each after becoming paraplegics, three already had children before their paraplegia. Two of the 22 babies were stillborn. One died in utero in a traumatic paraplegia below $\mathrm{T}_{5}$. The woman became pregnant again two years later and had a spontaneous premature delivery of a healthy girl. The other stillborn baby was a breech birth at home to a woman of 20 with a complete paraplegia below Ti2 who did not realise that she was in labour and did not send for the nurse until the baby was born. In fact, the husband discovered this on his return from work.

With regard to potency and sterility, I have also previously described (I960) that over 50 per cent. of a total of 90 paraplegics and tetraplegics were not sterile, as found by the intrathecal Prostigmin test (described 1953). As shown by the present statistics, it is obvious that men with complete and in particular incomplete lesions can sire their own children. Already in 1944, when the question of marriage of paraplegic soldiers arose, I could not accept the general attitude that paraplegics should be dissuaded from marrying, and the following case was a great encouragement in this respect. A young soldier with a cauda equina lesion below $\mathrm{L}_{5}$ was admitted with a suprapubic cystostomy from the battlefront. He had just been married before being called up to the Army, and after he received his severe injury 
he wanted to give his young wife a divorce, because he thought it would be unfair to her to remain tied to him. I persuaded him to wait until the suprapubic cystostomy was withdrawn, which we succeeded in doing, and he made a good re-education of his bladder as well as an excellent adjustment to his remaining disability, being able to walk. He was sent home on leave, which he accepted with extreme reluctance, but after his return he was a dramatically changed man because he had realised that he could continue his marital activities. To conclude the story, he produced his first child within a year and on discharge home took up a job in a shoe-repairing department, having been a bricklayer before. One day I received a terse telegram-'Twins, Sir-Bill'! Altogether, he has had four children.

As with some able-bodied married couples, it may take several years before pregnancy is achieved. In this respect, my first patient-a soldier with a cauda equina lesion below $\mathrm{L}_{2}$ on the right and $\mathrm{L}_{3}$ on the left, who was admitted on the 3rd February I944-may be quoted. He, too, was admitted with a suprapubic cystostomy, which was successfully closed, and his urine became sterile. He was married just before the war and his wife was very devoted to him. In I954, he informed me very happily of the birth of a daughter. Unfortunately, the baby died a few months later of an intestinal obstruction.

A very important achievement is that today, having regard to the great advances made in the rehabilitation of paraplegics and in restoring their working capabilities, Adoption Societies take a different and more co-operative view towards the adoption of children by paraplegics than they took only ten years ago. In this respect, it may be mentioned that we have patients in our material who were married before their paraplegia and had children. As the couples wanted more children and this could not be achieved in the normal way, they adopted children, and in all cases this has proved most successful. Even in these cases, the Adoption Societies have co-operated well.

In conclusion, it has been proved beyond all doubt that paraplegics and even tetraplegics make very satisfactory partners in marriage, and this applies to marriages both before and after injury. Their marriages are, of course, subject to all the problems encountered in marriages of the able-bodied, but their divorce rate is not significantly higher. Some paraplegics and even tetraplegics are able to sire their own children, and female paraplegics and tetraplegics are able to bear children in the normal way. Having regard to the advances made in the rehabilitation of these severely disabled people, Adoption Societies now show more understanding and co-operation in allowing paraplegics to adopt children.

\section{REFERENCES}

COMARr, E. \& Bors, E. (1955). F. Urol. 73, I72.

Comarr, E. (1962). Proc. I Ith Ann. Clin. Spinal Cord Conference. Veterans Administration Hospital, Bronx, New York, p. 209 and 2 I I.

Guttmann, L. (I953). British History of World II, Vol. Surgery, pp. 282-286. London: Her Majesty's Stationery Office.

Guttmann, L. (I960). The Sexual Problem in Spinal Paraplegia. Scientific Meeting during Stoke Mandeville Games, Rome, pp. 65-69.

Guttmann, L. (1963). Proc. R. Soc. Med. 5, 383-387.

Munro, D., Horne, H., \& Paul, P. (I948). New Eng. F. Med. 239, 903.

TALBOT, H. (1955). F. Urol. 73, 9I.

Zeitlin, B., CotTRell, T. \& Lloyd, F. (I957). Fertility and Sterility, Vol. 8, pp. 337-344. New York: Hoeber. 